\title{
Rapid progression of midventricular obstruction in adults with double-chambered right ventricle
}

\author{
José María Oliver, MD \\ Ana Garrido, MD \\ Ana González, MD \\ Fernando Benito, MD \\ Marta Mateos, MD \\ Angel Aroca, MD \\ Ernesto Sanz, MD
}

From the Adult Congenital Heart Disease Unit, Hospital Universitario La Paz, Madrid, Spain.

Received for publication May 29, 2002; revisions requested Aug 1, 2002; revisions received Sept 5, 2002; accepted for publication Sept 17, 2002.

Address for reprints: Dr José María Oliver, Unidad Médico-Quirúrgica de Cardiología, Hospital Universitario La Paz, La Castellana 261, Madrid 28046, Spain (E-mail: pepeoliver@jet.es).

J Thorac Cardiovasc Surg 2003;126:711-7

Copyright (๑) 2003 by The American Association for Thoracic Surgery

$0022-5223 / 2003 \$ 30.00+0$

doi:10.1016/S0022-5223(03)00044-8
Objective: The purpose of this study was to determine the rate of progression of midventricular obstruction in adolescents and adults with double-chambered right ventricle.

Methods: Clinical and echocardiographic findings in 45 patients (mean age $26 \pm 6$ years, range 15-44) diagnosed with double-chambered right ventricle were retrospectively analyzed. Twenty patients underwent surgical repair before the age of 15 years. The relationship between Doppler midventricular pressure gradient and patient age was analyzed in 25 patients without previous repair. Sequential change in midventricular obstruction was determined for patients with 2 or more Doppler echocardiographic examinations performed within at least a 2-year interval.

Results: Right midventricular pressure gradient in nonrepaired patients was $70 \pm 38$ $\mathrm{mm} \mathrm{Hg}$ (range 25-150). A significant relationship between midventricular obstruction and patient age $(\mathrm{r}=0.64, P<.001)$ was found. Midventricular pressure gradient at initial evaluation was $32 \pm 27 \mathrm{~mm} \mathrm{Hg}$ in 16 patients $<25$ years and 73 $\pm 45 \mathrm{~mm} \mathrm{Hg}$ in 9 patients $\geq 25$ years $(P<.03)$. After the initial study, 5 patients underwent surgical repair and 13 patients without repair were followed up for a period of $6.1 \pm 2.7$ years (range 2-9), in which midventricular pressure gradient increased from $32 \pm 26 \mathrm{~mm} \mathrm{Hg}$ to $67 \pm 35 \mathrm{~mm} \mathrm{Hg}(P<.001)$. The slope of the change in midventricular pressure gradient was $6.2 \pm 3 \mathrm{~mm} \mathrm{Hg}$ per year of follow-up. Seven more patients underwent surgical repair during follow-up due to progression of the obstruction. There was no mortality nor residual midventricular obstruction in surgically repaired patients.

Conclusions: Mild right midventricular obstruction shows a fast rate of progression in adolescents and young adults. Thus, close clinical and echocardiographic follow-up is advised, and surgical repair should be considered if significant progression of obstruction is detected.

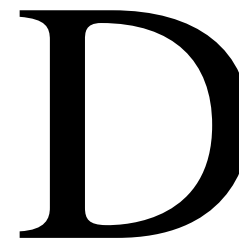

ouble-chambered right ventricle (DCRV) is a relatively rare cardiac anomaly consisting of right midventricular obstruction due to anomalous muscle bands that divide the right ventricle into a proximal high-pressure chamber and a low-pressure distal chamber. ${ }^{1-3}$ This entity, as discrete subaortic stenosis, ${ }^{4}$ is currently considered an "acquired" cardiac defect of postnatal development. ${ }^{5}$ Double-chambered right ventricle has been well documented in infants and children with perimembranous ventricular septal defect, where the prevalence is high and the midventricular obstruction progresses rapidly. ${ }^{6,7}$ It has also been described in malalignment-type ventricular septal defect ${ }^{8}$ and after repair of tetral- 
TABLE 1. Mean age, gender distribution, and associated congenital heart disease in patients with double-chambered right ventricle operated during infancy or childhood (group I) and naturally surviving until adulthood (group II)

\begin{tabular}{lccc}
\hline & $\begin{array}{c}\text { Overall } \\
(\mathbf{n}=\mathbf{4 5})\end{array}$ & $\begin{array}{c}\text { Group I } \\
(\mathbf{n = 2 0 )}\end{array}$ & $\begin{array}{c}\text { Group II } \\
(\mathbf{n}=\mathbf{2 5})\end{array}$ \\
\hline Gender (\% male) & $44 \%$ & $45 \%$ & $44 \%$ \\
Age (years) & $23 \pm 8$ & $20 \pm 7$ & $25 \pm 8$ \\
Associated CHD & $40(89 \%)$ & $18(90 \%)$ & $22(88 \%)$ \\
$\quad$ Ventricular septal defect & 37 & 18 & 19 \\
Discrete subaortic stenosis & 6 & 3 & 3 \\
Atrioventricular septal defect & 1 & - & 1 \\
Ruptured Valsalva sinus aneurysm & 1 & - & 1 \\
Supravalvar pulmonary stenosis & 1 & - & 1 \\
\hline
\end{tabular}

CHD, Congenital heart disease.

ogy of Fallot. ${ }^{9}$ Mechanisms for development and progression of right midventricular obstruction ${ }^{10-13}$ are not as well established as those for discrete subaortic stenosis, ${ }^{14-19}$ but both entities frequently coexist ${ }^{20-22}$ and probably share a similar pathogenesis. ${ }^{6,23}$ The rate of progression of right midventricular obstruction in adults has not been studied so far, as only a few cases of DCRV first diagnosed during adulthood have been previously described. ${ }^{24-28}$ Doppler echocardiography is a very useful tool for evaluation and follow-up of patients with DCRV. ${ }^{29}$ The aim of this study was to determine the rate of progression of right midventricular obstruction in patients diagnosed with DCRV without surgical correction during infancy or childhood.

\section{Methods}

\section{Study Population}

All patients diagnosed with DCRV from January 1990 to December 2000 were identified from the database of the Adult Congenital Heart Diseases Unit at La Paz University Hospital, Madrid. This study included only patients who were older than 15 years and who had DCRV diagnosed either by Doppler echocardiography or during surgical intervention. DCRV was diagnosed when an anomalous muscle band was identified crossing the right ventricular cavity from the ventricular septum to the parietal wall, producing a significant midventricular obstruction, in patients with normal infundibulum and pulmonary valve. Patients with ventricular or atrioventricular septal defects were included, but other truncoconal malformations were excluded. All the included patients had at least 1 follow-up visit and a Doppler echocardiographic study.

Included patients were classified into 2 groups: group I included all patients who had been diagnosed with DCRV before the age of 15 years, and group II included all patients first diagnosed with DCRV after the age of 15 years. Age, gender distribution, frequency of other associated congenital heart diseases, and need for surgical intervention during follow-up were determined. To calculate the prevalence of DCRV among adults with congenital heart disease, we determined the number of adult patients for whom a Doppler echocardiogram had been obtained during the same period and who had been diagnosed with congenital heart defect.

\section{Doppler Echocardiography}

Comprehensive 2-dimensional and Doppler echocardiographic assessment were performed with a Sonos 1000, 2500, or 5500 ultrasound system (Philips, Andover, Mass) fitted with a $2.5-\mathrm{MHz}$ or a multifrequency probe. Right midventricular obstruction was evaluated by continuous wave Doppler obtained from the subcostal or high parasternal position, and peak pressure gradient was determined by Bernoulli's simplified equation. ${ }^{30}$ To study the progression of right midventricular obstruction during adulthood, we determined in patients of group II: (1) the relationship between patient age at the initial study and Doppler right midventricular pressure gradient; (2) the difference in right midventricular pressure gradient between patients who were $<25$ years old and patients $\geq 25$ years; (3) the changes in right midventricular pressure gradient with time for those patients who had 2 or more presurgical Doppler echocardiograms separated by an interval $\geq 2$ years; and (4) the slope of change in right midventricular pressure gradient over time.

\section{Statistical Analysis}

Group data are presented as the mean value \pm standard deviation. The prevalence of DCRV, gender distribution, and frequency of associated congenital heart diseases were expressed in terms of percentages. The relationship between age and Doppler midventricular pressure gradient was analyzed using linear regression. Student $t$ test was used for comparing right midventricular pressure gradient between 2 age arbitrary groups (patients $<25$ years old and patients $\geq 25$ years old). Changes in right midventricular pressure gradient from the initial to late studies were analyzed using the paired $t$ test. The slope of change in Doppler midventricular pressure gradient over time was calculated as the mean value \pm standard deviation of the change observed between the late and initial study, divided by the delay between the studies. For each of the analyses, $P<.05$ was considered statistically significant.

\section{Results}

A total of 45 patients $\geq 15$ years old diagnosed with DCRV, who had at least 1 Doppler echocardiographic assessment between January 1990 and December 2000, were identified. Their mean age was $26 \pm 6$ years (range 15-44). There were 20 male patients and 25 female patients. The number of patients having a congenital heart disease diagnosis during the same period was 2169, bringing the prevalence of DCRV among adults with congenital heart defects to $2.1 \%$. There were 20 patients who had been diagnosed with DCRV during infancy and childhood (group I) and 25 naturally surviving patients first diagnosed with DCRV after the age of 15 years (group II).

\section{Associated Heart Diseases}

There were a total of 40 patients $(89 \%)$ with another congenital heart disease (Table 1). The most frequently associ- 
TABLE 2. Changes in right midventricular obstruction in 13 patients who had two Doppler echocardiographic assessments separated by an interval of at least 2 years

\begin{tabular}{|c|c|c|c|c|c|}
\hline Patient No. & $\begin{array}{c}\text { Age } \\
\text { (years) }\end{array}$ & $\begin{array}{c}\text { Initial MVPG } \\
\text { (mm Hg) }\end{array}$ & $\begin{array}{l}\text { Follow-up MVPG } \\
(\mathrm{mm} \mathrm{Hg})\end{array}$ & $\begin{array}{l}\text { Interval } \\
\text { (years) }\end{array}$ & $\begin{array}{c}\text { Annual change } \\
(\mathrm{mm} \mathrm{Hg})\end{array}$ \\
\hline 1 & 30 & 33 & 80 & 9 & 5.2 \\
\hline 2 & 21 & 0 & 32 & 6 & 5.3 \\
\hline 3 & 20 & 25 & 40 & 5 & 3.0 \\
\hline 4 & 18 & 36 & 80 & 4 & 11.0 \\
\hline 5 & 18 & 0 & 25 & 3 & 8.3 \\
\hline 6 & 32 & 40 & 70 & 9 & 3.3 \\
\hline 7 & 21 & 66 & 91 & 5 & 5.0 \\
\hline 8 & 24 & 0 & 35 & 9 & 3.9 \\
\hline 9 & 40 & 50 & 150 & 9 & 11.1 \\
\hline 10 & 36 & 80 & 100 & 2 & 10.0 \\
\hline 11 & 24 & 35 & 75 & 6 & 6.7 \\
\hline 12 & 24 & 0 & 35 & 9 & 3.9 \\
\hline 13 & 21 & 45 & 55 & 3 & 3.3 \\
\hline Mean $\pm S D$ & $25 \pm 7$ & $32 \pm 26$ & $67 \pm 35^{*}$ & $6.1 \pm 2.7$ & $6.2 \pm 3.0$ \\
\hline
\end{tabular}

$M V P G$, Midventricular pressure gradient.

${ }^{*} P<.001$ compared with initial MVPG value.

ated cardiac defect was a perimembranous ventricular septal defect $(\mathrm{n}=37)$, but ventricular septum was intact in 7 patients: 2 in group I (10\%) and 5 in group II (20\%). Six patients had an associated discrete subaortic stenosis $(15 \%)$ : 3 in group I and 3 in group II. One patient in group II presented an aortic sinus of Valsalva aneurysm ruptured into the right ventricle and another patient, also in group II, presented a supravalvular pulmonary stenosis.

\section{Right Midventricular Obstruction}

All patients in group I underwent surgical repair of DCRV before the age of 15 years. Only 1 of 20 patients in this group had a significant right midventricular obstruction when evaluated during adulthood. This patient had been operated on at 7 years of age with a right ventricular to pulmonary artery conduit because of an associated coronary anomaly. Severe conduit obstruction was detected 13 years later, and the patient was reoperated on by transatrial approach for resection of the anomalous muscle bundle and right midventricular hypertrophy.

Doppler right midventricular pressure gradient in 25 patients of group II was $70 \pm 38 \mathrm{~mm} \mathrm{Hg}$ (range 25-150). A significant relationship $(\mathrm{r}=0.64, P<.001)$ between age at the initial study and right midventricular pressure gradient was found in this group of patients. The initial midventricular pressure gradient was $32 \pm 27 \mathrm{~mm} \mathrm{Hg}$ in 16 patients $<25$ years old compared with $73 \pm 45 \mathrm{~mm} \mathrm{Hg}(P<.03)$ in 9 patients $\geq 25$ years old.

\section{Follow-up}

After the initial study, 5 patients underwent surgical repair and 13 patients were followed up for at least 2 years. Table 2 shows changes in right midventricular pressure gradient of
13 patients who had at least 2 Doppler echocardiographic examinations separated by an average interval of $6.1 \pm 2.7$ years (range 2-9). Although there was a wide range of variation in midventricular obstruction during the followup, there was a significant increase in Doppler midventricular pressure gradient from $32 \pm 26 \mathrm{~mm} \mathrm{Hg}$ at the initial study to $67 \pm 35 \mathrm{~mm} \mathrm{Hg}$ at the end of follow-up (average increase $35 \pm 22 \mathrm{~mm} \mathrm{Hg}, 95 \%$ confidence interval 22 to 49 , $P<.001)$. The slope of change in Doppler midventricular pressure gradient was $6.2 \pm 3.0 \mathrm{~mm} \mathrm{Hg}$ per year of followup. Figure 1 shows the progression in midventricular obstruction together with the changes in the 12-lead electrocardiogram after 9 years of follow-up in a representative patient. During follow-up, 7 more patients underwent surgical repair due to severe progression of obstruction. There was neither mortality nor residual right midventricular obstruction after surgical repair during adulthood.

\section{Discussion}

To our knowledge, this series represents the largest experience for DCRV in adults. Overall, the data from this study suggest that DCRV is a relatively frequent cardiac defect in adolescents and young adults, with prevalence close to $2 \%$ of all adult congenital heart diseases. It is characterized by a progressive midventricular obstruction usually associated with a perimembranous ventricular septal defect. The rate of progression of midventricular obstruction in young adults is fast, and severe right ventricular outflow tract obstruction may be anticipated during the third or fourth decade of life in most cases. Transatrial surgical repair should be advised when significant progression of midventricular obstruction is detected by Doppler echocardiography. 


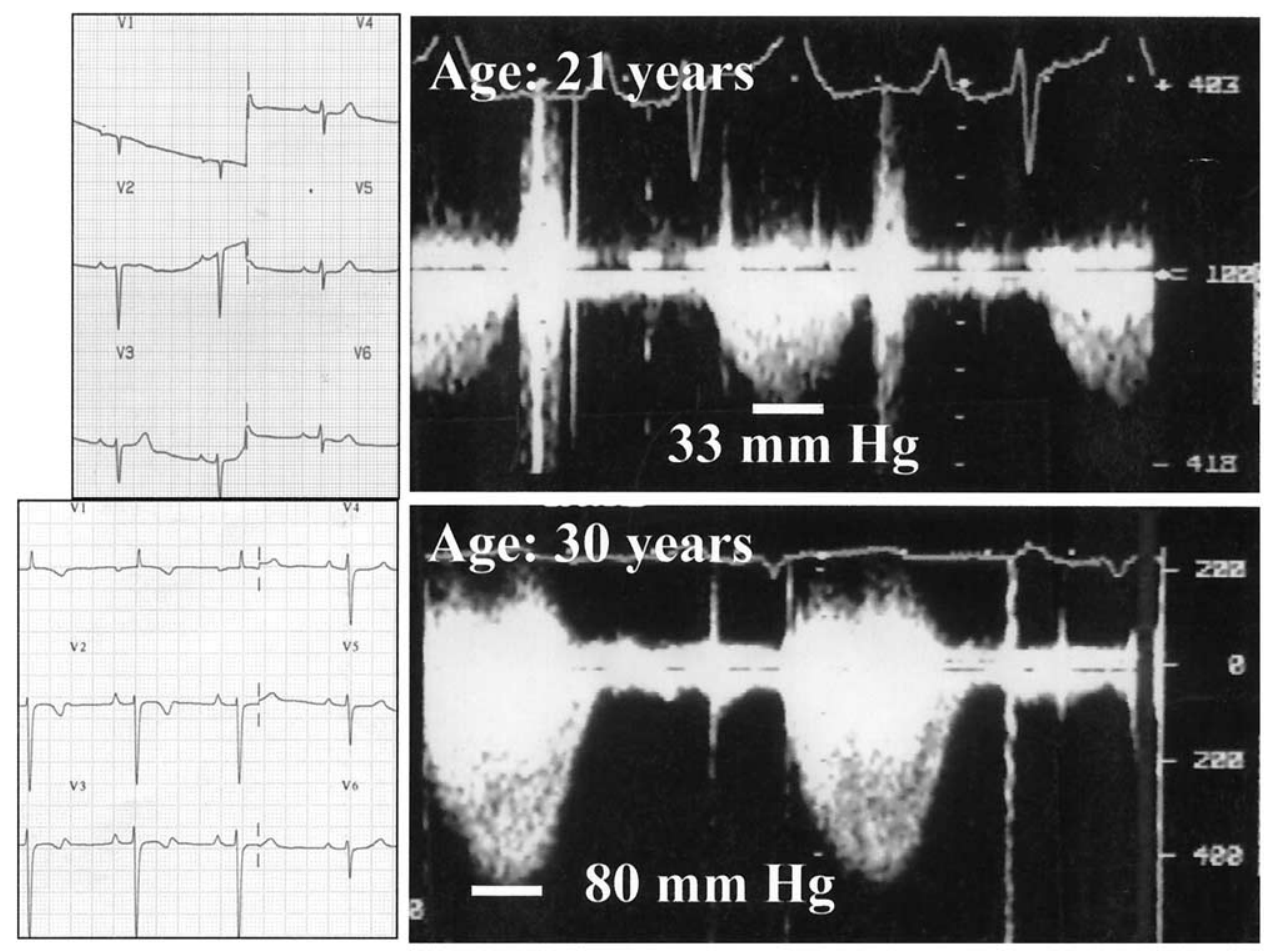

Figure 1. Changes in electrocardiographic precordial leads and Doppler right midventricular obstruction after 9 years of follow-up in a young adult with double-chambered right ventricle. Peak Doppler pressure gradient increased from $33 \mathrm{~mm} \mathrm{Hg}$ to $80 \mathrm{~mm} \mathrm{Hg}$. Initial electrocardiogram was normal, but right ventricular hypertrophy may be noted in the follow-up evaluation.

\section{Diagnosis}

Diagnosis of DCRV in this study was based on Doppler echocardiographic or surgical examination. Clinical findings are not usually impressive in adult patients without severe obstruction. A high-grade holosystolic murmur at the left parasternal border is frequently attributed to a preexistent ventricular septal defect. Two-dimensional and Doppler echocardiographic diagnosis may be lost if a high right ventricular systolic pressure is attributed to pulmonary hypertension, and systolic turbulence at the mid-right ventricular cavity is attributed to the interventricular shunt. ${ }^{28} \mathrm{Care}-$ ful imaging of the right ventricle should reveal a muscular bundle crossing from the ventricular septum to the parietal wall, dividing the right ventricle in 2 chambers, but differentiation from normal septoparietal trabeculations may be difficult. On parasternal echocardiogram views, color Doppler flow of the interventricular shunt and midventricular obstruction frequently overlap, and peak velocity of the obstructive jet is usually underestimated. Subcostal approach is much better for differentiating interventricular and midventricular Doppler flow jets, imaging muscle bundle across the right ventricle, and recording peak velocity of midventricular obstruction. ${ }^{23,31,32}$ In difficult adult cases, transesophageal approach may be very useful ${ }^{33,34}$ (Figure 2).

\section{Prevalence}

This cardiac defect typically presents in infancy and childhood, with prevalence estimated in $10 \%$ of children undergoing correction of a ventricular septal defect, ${ }^{35} 3.1 \%$ after repair of tetralogy of Fallot, ${ }^{9}$ and less than $1 \%$ of all cardiac defects in infancy or childhood. ${ }^{22}$ Prevalence of DCRV in adults has not been yet studied, and only a few cases with DCRV first diagnosed during adulthood have been previously described. ${ }^{24-28}$ We found 45 patients diagnosed with DCRV out of 2169 consecutive adults with congenital heart disease, bringing the prevalence of DCRV to $2.1 \%$. Diagnosis of this cardiac lesion was first made after the age of 15 years in 25 patients, and it was, as a matter of fact, the leading cause of surgical repair in adults with ventricular septal defect at our institution. ${ }^{36}$

\section{Association with Other Cardiac Defects}

DCRV is typically associated with perimembranous or malalignment ventricular septal defect, ${ }^{6-8}$ but association with tetralogy of Fallot, ${ }^{9}$ pulmonary valve stenosis, atrial septal defect, and double-outlet right ventricle have also been reported. ${ }^{37}$ In the current study, patients with pulmonary valve stenosis or truncoconal malformations were excluded, but ventricular or atrioventricular septal defects were 
present in 38 cases $(84 \%)$. An intact ventricular septum is very uncommon in DCRV; it is more frequently reported in adults than in children. In our study, ventricular septum was intact in $20 \%$ of naturally surviving patients compared with $10 \%$ of patients operated on during infancy or childhood but the difference was not significant. Most of the naturally surviving patients had a restrictive or near-closed ventricular septal defect; thus, an intact ventricular septum probably represents a spontaneously sealed ventricular septal defect. The association between DCRV and discrete subaortic stenosis has been reported to be 9 times greater than expected, ${ }^{20}$ and it was found in $15 \%$ of our series. This association has special significance to explain the development and progression of DCRV.

\section{DCRV Development}

Although prenatal diagnosis of subvalvular right ventricular outflow tract obstruction has been described in cases of polyhydramnios and twin-twin transfusion syndrome, ${ }^{38,39}$ current consensus considers DCRV an acquired cardiac defect of postnatal development. ${ }^{5,10-13}$ Morphologic studies have shown that the abnormal muscle bundle probably represents accentuated septoparietal trabeculations or a hypertrophic and displaced moderator band. ${ }^{1,12,13,40}$ Most patients have associated ventricular septal or truncoconal malformations when diagnosis of DCRV is performed, and Wong and colleagues ${ }^{12}$ have shown that patients with ventricular septal defect who develop DCRV have a superior and rightward displacement of the septal insertion of the moderator band. Thus, both morphologic substrate and flow disturbance in right ventricular outflow tract seem to be necessary for DCRV development. The pathogenic mechanisms of DCRV development seem quite similar to those of discrete subaortic stenosis. ${ }^{14-19}$ In both entities, different morphological alterations can cause changes in fluid dynamic factors that increase muscular shear stress and trigger a basic genetic predisposition to developing cellular growth factors. The frequent coexistence of DCRV and discrete subaortic stenosis may indicate a high genetic predisposition toward cellular proliferation.

\section{Rate of Progression of Midventricular Obstruction in Adults}

Rapid progression of right midventricular obstruction has been well established in infants and children, ${ }^{1,3,5}$ but natural progression during adult life has not been previously reported. We have recently shown that discrete subaortic stenosis progresses in severity along the lifetime but, in contrast to what happens in children, the progression of the obstruction occurs slowly in adults. ${ }^{41}$ The present study shows that DCRV may also have a progressive nature during adult life, but the rate of progression is much faster. In both entities there was a significant relationship between patient age and Doppler-estimated pressure gradient, but the

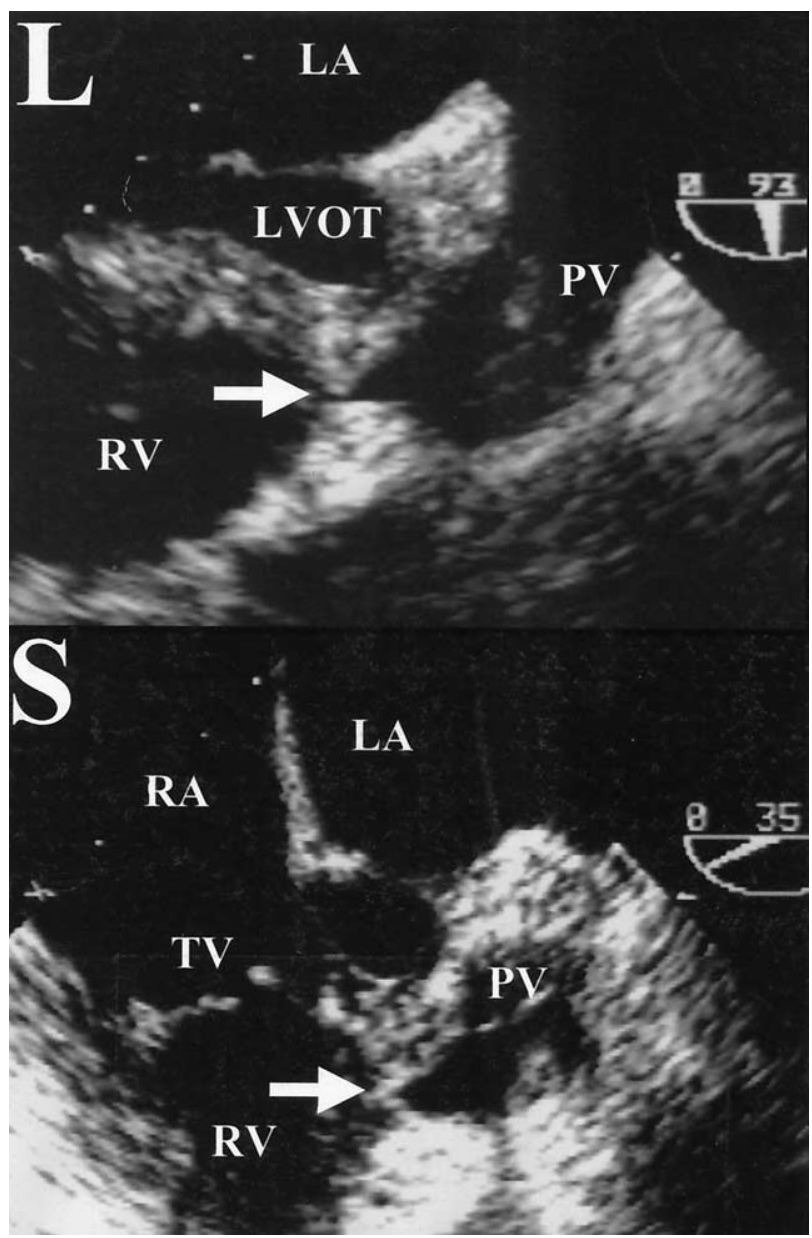

Figure 2. Multiplane transesophageal echocardiography in long (L) and short (S) axis views of the right ventricular outflow tract in a patient with double-chambered right ventricle showing severe midventricular obstruction (arrows) and normal infundibulum and pulmonary valve (PV). LA, Left atrium; $L V O T$, left ventricular outflow tract; $R A$, right atrium; $R V$, right ventricle; $T V$, tricuspid valve.

slope of linear regression was 3 times steeper in DCRV than in discrete subaortic stenosis. Most patients $<25$ years old with DCRV had mild midventricular obstruction, but 7 of 9 patients $>25$ years old and all patients $>30$ years old, at the last evaluation, had a Doppler midventricular pressure gradient $\geq 70 \mathrm{~mm} \mathrm{Hg}$. In patients with sequential studies, covering time intervals from 2 to 9 years, there was a significant increase in right midventricular pressure gradient of $35 \pm 22 \mathrm{~mm} \mathrm{Hg}$ (95\% confidence interval 22 to 49), and change in the pressure gradient was much steeper in DCRV $(6.2 \pm 3.0 \mathrm{~mm} \mathrm{Hg}$ per year) than in discrete subaortic stenosis $(2.25 \pm 4.7 \mathrm{~mm} \mathrm{Hg}$ per year $) .{ }^{41}$ Moreover, a large number of patients with DCRV who were first diagnosed after the age of 15 years underwent surgical repair during 
follow-up, and no patients older than 50 years who survived naturally without operation were found in this series.

\section{Limitations of the Study}

A number of biases are present in the current study. Patient group with natural survival into adulthood is relatively small, and the retrospective nature of the study may be considered an important limitation. A larger series with a prospective design would probably address the nature of progression more adequately. Hemodynamic data were based only on Doppler echocardiographic assessment, and data from cardiac catheterization were not analyzed. Fair correlation between Doppler and catheter-based right ventricular outflow tract pressure gradient has previously been reported ${ }^{42}$ although the Doppler maximal gradient consistently overestimated the peak-to-peak catheter gradient by as much as $25 \%$ to $40 \%{ }^{43}$ However, preoperative cardiac catheterization was performed in all surgical patients, and Doppler-indicated severity of midventricular obstruction was confirmed in every case. Finally, by including patients of 15 years of age at initial evaluation, it could be expected that they had not yet reached their adult size and some growth continued to occur, explaining some increase in gradient.

\section{Surgical Implications}

Transatrial repair of DCRV can be accomplished with a very low rate of morbidity and satisfactory long-term postoperative results. ${ }^{44-48}$ In this series, only 1 of 20 patients with surgical repair during childhood and none of 12 patients operated on during adulthood had significant postoperative midventricular obstruction. Due to the rapid rate of progression in midventricular obstruction shown in this study, adolescents and young adults with mild right midventricular Doppler pressure gradient should have a very close clinical and echocardiographic follow-up, and surgical repair should be advised if significant progression of obstruction is detected. A reasonable approach to management of right midventricular obstruction in young adults might include surgical removal of the obstruction when Doppler peak pressure gradient is $\geq 50 \mathrm{~mm} \mathrm{Hg}$ or right ventricular systolic pressure become $\geq 50 \%$ of systolic blood pressure.

\section{References}

1. Lucas RV, Varco RL, Lillehei CW, Adams P, Anderson RC, Edwards JE. Anomalous muscle bundle of the right ventricle. Circulation. 1962;25:443-55.

2. Hartmann AF, Tsifutis AA, Arvidsson H, Goldring D. The twochambered right ventricle: a report of nine cases. Circulation. 1963; 26:279-87.

3. Hartmann AF, Goldring D, Carlsson E. Development of right ventricular obstruction by aberrant muscular bands. Circulation. 1964;30: 679-85.

4. Firpo C, Azcarate MJ, Quero-Jimenez M, Saravalli O. Discrete subaortic stenosis (D.S.S.) in childhood: a congenital or acquired disease? Follow-up in 65 patients. Eur Heart J. 1990;11:1033-40.
5. Pongiglione G, Freedom RM, Cook D, Rowe RD. Mechanism of acquired right ventricular outflow tract obstruction in patients with ventricular septal defect: an angiocardiographic study. Am J Cardiol. 1982;50:776-80.

6. Perloff JK, Ronan JA Jr, De Leon AC. Ventricular septal defect with the "two-chambered right ventricle." Am J Cardiol. 1965;16:894-900.

7. Shepherd RL, Glancy DL, Jaffe RB, Perloff JK, Epstein SE. Acquired subvalvular right ventricular outflow obstruction in patients with ventricular septal defect. Am J Med. 1972;53:446-55.

8. Wang JK, Wu MH, Chang CI, et al. Malalignment-type ventricular septal defect in double-chambered right ventricle. Am J Cardiol. 1996;77:839-42.

9. Moran AM, Hornberger LK, Jonas RA, Keane JF. Development of a double-chambered right ventricle after repair of tetralogy of Fallot. J Am Coll Cardiol. 1998;31:1127-33.

10. Hindle WV, Engle MA, Hagstrom JWC. Anomalous right ventricular muscles. A clinicopathologic study. Am J Cardiol. 1968;21:487-95.

11. Rowland TW, Rosenthal A, Castaneda AR. Double-chambered right ventricle: experience with 17 cases. Am Heart J. 1975;89:155-62.

12. Wong PC, Sanders SP, Jonas RA, et al. Pulmonary valve-moderator band distance and association with development of double-chambered right ventricle. Am J Cardiol. 1991;68:1681-6.

13. Alva C, Ho SY, Lincoln CR, Rigby ML, Wright A, Anderson RH. The nature of the obstructive muscular bundles in double-chambered right ventricle. J Thorac Cardiovasc Surg. 1999;117:1180-9.

14. Borow KM, Glagov S. Discrete subvalvular aortic stenosis: is the presence of upstream complex blood flow disturbances an important pathogenic factor? J Am Coll Cardiol. 1992:825-7.

15. Gewillig M, Daenen W, Dumoulin M, Van der Hauwaert L. Rheologic genesis of discrete subvalvular aortic stenosis: a Doppler echocardiographic study. J Am Coll Cardiol. 1992;19:818-24.

16. Kleinert S, Geva T. Echocardiographic morphometry and geometry of the left ventricular outflow tract in fixed subaortic stenosis. J Am Coll Cardiol. 1993;22:1501-8.

17. Sigfusson G, Tacy TA, Vanauker MD, Cape EG. Abnormalities of the left ventricular outflow tract associated with discrete subaortic stenosis in children: an echocardiographic study. J Am Coll Cardiol. 1997;30: 255-9.

18. Cape EG, Vanauker MD, Sigfusson G, et al. Potential role of mechanical stress in the etiology of pediatric heart disease: septal shear stress in subaortic stenosis. J Am Coll Cardiol. 1997;30:247-54.

19. Bezold LI, Smith EO, Kelly K, et al. Development and validation of an echocardiographic model for predicting progression of discrete subaortic stenosis in children. Am J Cardiol. 1998;81:314-20.

20. Baumstark A, Fellows KE, Rosenthal A. Combined double chambered right ventricle and discrete subaortic stenosis. Circulation. 1978;57: 299-303.

21. Corone S, Corone P, Dor X, Leriche H, Binet JP, Planche C. Ventricule droit a double chambre, stenose sous-valvulaire aortique et communication interventriculaire. A Propos de 12 cas. Arch Mal Coeur Vaiss. 1993;86:609-16.

22. Cabrera A, Martinez P, Rumoroso JR, et al. Double-chambered right ventricle. Eur Heart J. 1995;16:682-6.

23. Galiuto L, O'Leary PW, Seward JB. Double-chambered right ventricle: echocardiographic features. J Am Soc Echocardiogr. 1996;9: 300-5.

24. Osborn RC Jr, Taylor J, Soto B, Burnum JF. Double chambered right ventricle in a 70-year-old woman. Ala J Med Sci. 1984;21:73-7.

25. Simarro E, Simarro C, Moris C. Double-chamber right ventricle in a 63-year-old woman. Acta Cardiol. 2000;55:39-40.

26. McElhinney DB, Chatterjee KM, Reddy VM. Double-chambered right ventricle presenting in adulthood. Ann Thorac Surg. 2000;70:124-7.

27. Kalaria VG, Mendelsohn A, Peterson J, Ling FS. Double-chambered right ventricle in an adult patient. J Invasive Cardiol. 2001;13:111-3.

28. Kucher N, Seiler C, Allemann Y, Eberli FR. Double-chambered right ventricle. Circulation. 2001;103:105-6.

29. Snider AR, Serwer GA, Ritter SB. Echocardiographic in pediatric heart disease. 2nd ed. St Louis: Mosby; 1997.

30. Hatle L, Angelsen B. Doppler ultrasound in cardiology. 2nd ed. Philadelphia: Lea \& Febiger; 1985.

31. Shimada R, Tajimi T, Koyanagi S, et al. Two-dimensional echocar- 
diographic findings in double-chambered right ventricle. Am Heart J. 1984;108:1059-61.

32. Matina D, van Doesburg NH, Fouron JC, Guerin R, Davignon A. Subxiphoid two-dimensional echocardiographic diagnosis of doublechambered right ventricle. Circulation. 1983;67:885-8.

33. Chang RY, Kuo CH, Rim RS, Chou YS, Tsai CH. Transesophageal echocardiographic image of double-chambered right ventricle. $J$ Am Soc Echocardiogr. 1996;9:347-52.

34. Sreeram N, de Bruijn D, Hitchcock JF. Double chambered right ventricle: delineation by multiplane transoesophageal echocardiography. Int J Cardiol. 1998;66:309-11.

35. Simpson WF Jr, Sade RM, Crawford FA, Taylor AB, Fyfe DA Double-chambered right ventricle. Ann Thorac Surg. 1987;44:7-10.

36. Oliver J. Cardiopatías congénitas del adulto. Cambios en el espectro de las malformaciones cardiacas durante la vida adulta y análisis de las lesiones residuales, secuelas y complicaciones a largo plazo. Un estudio de 1500 pacientes consecutivos. Tesis Doctoral. Universidad $\mathrm{Au}-$ tónoma, Madrid, 1997.

37. Cil E, Saraclar M, Ozkutlu S, et al. Double-chambered right ventricle: experience with 52 cases. Int J Cardiol. 1995;50:19-29.

38. Marton T, Hajdu J, Papp Z. A rare case of non-immune hydrops fetalis: double-chambered right ventricle. a case report. Fetal Diagn Ther. 2001;16:251-3.

39. Lougheed J, Sinclair BG, Fung KFK, et al. Acquired right ventricular outflow tract obstruction in the recipient twin in twin-twin transfusion syndrome. J Am Coll Cardiol. 2001;38:1533-8.

40. Gallucci V, Scalia D, Thiene G, Mazzucco A, Valfre C. Double- chambered right ventricle: surgical experience and anatomical considerations. Thorac Cardiovasc Surg. 1980;28:13-7.

41. Oliver J, González A, Gallego P, Sanchez-Recalde A, Benito F, Mesa JM. Discrete subaortic stenosis in adults: increased prevalence and slow rate of progression of the obstruction and aortic regurgitation. J Am Coll Cardiol. 2001;38:835-42.

42. Lima CO, Sahn DJ, Valdes-Cruz LM, et al. Noninvasive prediction of transvalvular pressure gradient in patients with pulmonary stenosis by quantitative two-dimensional echocardiographic Doppler studies. Circulation. 1983;67:866-71.

43. Aldousany AW, DiSessa TG, Dubois R, Alpert BS, Willey ES, Birnbaum SE. Doppler estimation of pressure gradient in pulmonary stenosis: maximal instantaneous vs peak-to-peak, vs mean catheter gradient. Pediatr Cardiol. 1989;10:145-9.

44. Kveselis D, Rosenthal A, Ferguson P, Behrendt D, Sloan H. Longterm prognosis after repair of double-chamber right ventricle with ventricular septal defect. Am J Cardiol. 1984;54:1292-5.

45. Penkoske PA, Duncan N, Collins-Nakai RL. Surgical repair of doublechambered right ventricle with or without ventriculotomy. $J$ Thorac Cardiovasc Surg. 1987;93:385-93.

46. Ford DK, Bullaboy CA, Derkac WM, Hopkins RA, Jennings RB Jr, Johnson DH. Transatrial repair of double-chambered right ventricle. Ann Thorac Surg. 1988;46:412-5.

47. McGrath LB, Joyce DH. Transatrial repair of double-chambered right ventricle. J Card Surg. 1989;4:291-8.

48. Galal O, Al-Halees Z, Solymar L, et al. Double-chambered right ventricle in 73 patients: spectrum of the disease and surgical results of transatrial repair. Can J Cardiol. 2000;16:167-74. 